\title{
Transcriptional Characterization of the Notch Signaling Pathway in Rodent Multipotent Adult Progenitor Cells
}

\author{
Melinda HAJDU,,${ }^{1,2}$ Aernout LUTTUN, ${ }^{1}$ Beatriz PELACHO,${ }^{1}$ Terry C BURNS, ${ }^{1}$ Lucas CHASE,${ }^{1}$ \\ María GUTIÉRREZ-PÉREZ, ${ }^{3}$ Yuehua JIANG,${ }^{1}$ Todd LENVIK, ${ }^{1}$ Virág VAS, ${ }^{4}$ Ferenc UHER, ${ }^{4}$ Anna SEBESTYÉN,${ }^{2}$ \\ Catherine VERFAILLIE ${ }^{1,5}$
}

${ }^{1}$ Stem Cell Institute, University of Minnesota Medical School, Minneapolis, MN, USA; ${ }^{2} 1$ st Department of Pathology and Experimental Cancer Research, Semmelweis University, Budapest, Hungary; ${ }^{3}$ Hematology and Cell Therapy, Clínica Universitaria, University of Navarra, Pamplona, Spain; ${ }^{4}$ Stem Cell Biology Unit, National Medical Center, Budapest, Hungary; ${ }^{5}$ Stem Cell Institute, Catholic University of Leuven, Leuven, Belgium

The Notch signaling pathway is a multifunctional, evolutionarily conserved pathway, which plays an important role in development as well as stem cell biology. Multipotent adult progenitor cells (MAPCs) represent a unique stem cell population, which is capable of differentiating into cell types of the ectodermal, mesodermal and endodermal lineages in vitro, and contribute to most somatic cell types in vivo. Our aim was to characterize the gene expression of Notch signaling elements in rodent MAPCs. We show that transcripts for Notch-receptors, ligands, regulatory molecules of the pathway and the Hairy/Enhancer of Split-1 (HES-1) target gene are present in mouse and rat low-Oct 4 MAPCs. We found that mouse Notch3 and rat Notch1 transcripts increased when cells were cultured at high density for 48 to 96 hours. HES-1 and HES-related transcription factor-1 (HERP-1), transcriptional targets of Notch-signaling, were both elicited by immobilized Delta1 ligand. In addition, mRNA for Notch1 and Notch3 was also induced by Notch-signaling, suggesting the presence of regulatory feedback loops. Slight differences between mouse and rat derived MAPCs suggest that the exact function, transcriptional regulation and the fine-tuning of the signal may be species specific. Taken together, we characterized the gene expression profile of the Notch pathway in rodent low-Oct4-MAPCs, and showed that the pathway is functional and can be modulated. Our results provide an additional tool and a further basis for a better understanding of stem cell biology. (Pathology Oncology Research Vol 13, No 4, 302-310)

Key words: Notch, HES-1, multipotent adult progenitor cell, stem cell

\section{Introduction}

The Notch signaling pathway

Notch belongs to a family of evolutionarily conserved proteins that are involved in a number of cellular and developmental functions. ${ }^{1}$ In mammals, four Notch receptors

Received: Oct 10, 2007; accepted: Dec 5, 2007

Correspondence: Melinda Hajdu, 1st Department of Pathology and Experimental Cancer Research, Semmelweis University; Üllói út 26., 1085-Budapest, Hungary, Phone: +36-1-2661638 ext. 4430; Fax: +36-1-3171074. Email: melindahajdu@ freemail.hu

This work was supported by the Forum Engelberg/Gertrud von Speyr Foundation (Switzerland) and the National Science Foundation of Hungary (TS049887)
(Notch1-4) and five Notch ligands (Jagged1, Jagged2, Delta1, Delta3 and Delta4) have been identified. Upon ligand binding the receptor is proteolytically cleaved by a $\gamma$-secretase complex containing the Presenilin-1 or Presenilin-2 enzyme, and the intracellular domain of the receptor translocates into the nucleus of the receiving cell, where it binds to the CSL transcription factor (CBF1 in mammals, Suppressor of Hairless in Drosophila and Lag in Caenorhabditis elegans; also known as RВP-Jк), and converts the originally inhibitory complex into a transcriptional activator. ${ }^{2-4}$ The best characterized transcriptional targets belong to the Hairy/Enhancer of Split (HES) and the HESrelated repressor protein (HERP; also known as HES-related transcription factor with YPRW motif, HRT or Hey) 
families. ${ }^{4}$ HES and HERP are basic helix-loop-helix transcription factors that negatively regulate the expression of downstream target genes, such as tissue specific transcription factors, regulating lineage-specific differentiation. HES and HERP proteins also repress transcription through the formation of homodimers and binding DNA directly - such direct target genes may be the Mash1 proneural transcription factor and the CD4 protein in T-cells. Indirect repression is also possible by binding and sequestering other transcription factors - for example the muscle-specific factor MyoD, or the coactivator $\mathrm{p} 300$ - and preventing their complex formation with transcriptional partners. ${ }^{4,5}$

Several molecules have been described which regulate Notch function. Deltex is an E3 ubiquitin ligase, which may cooperate with Notch both in an agonistic and antagonistic manner, and may participate in signaling pathways - at least in part - independently of Notch. ${ }^{6}$ The Numb adapter protein promotes the ubiquitination and degradation of Notch1, thereby negatively regulating Notch function. ${ }^{7,8}$ Signal transduction can be differentially modulated through receptor glycosylation by the family of the Fringe glycosyl-transferases (Lunatic, Manic and Radical Fringe), attenuating Jagged-mediated signaling and potentiating Delta-mediated signaling. ${ }^{9}$

The importance of Notch signaling in stem cells and cell fate specification

Throughout development, Notch-signaling regulates cell fate determination by inhibiting differentiation along default pathways, and allowing cells to adopt alternative cells fates when proper signals are delivered. ${ }^{10}$ This phenomenon is called lateral inhibition. However, Notch can also instructively promote cell differentiation, such as during glial development. ${ }^{11}$ The diverse roles of Notch in stem cell systems and in embryonic development are highlighted by a number of studies involving genetically engineered animals and in vitro approaches. ${ }^{12}$

Several stem cell types were shown to express elements of the Notch pathway. ${ }^{12-14}$ Notch1, 2 and 3 receptors, Delta1 and HES-1 were identified in embryonic stem cells (ESCs) on the mRNA or protein level. ${ }^{14-16}$ Many components of the Notch pathway are also expressed in the precursor cells of the developing vertebrate central nervous system, ${ }^{17}$ and the activity of the pathway is required for the maintenance, but not the generation, of mouse neural stem cells, and it promotes survival of neural stem cells in vitro and in vivo. ${ }^{18,19}$ Cancer stem cells share several properties with normal, nonneoplastic stem cells, and they have been implicated to utilize similar signaling pathways. Interestingly, the blockade of Notch signaling results in the depletion of stem-like cells and suppresses tumor formation in medulloblastomas, which are thought to arise from primitive neural stem or precursor cells. ${ }^{20}$ The delicate balance between stem cell self-renewal and differentiation has to be tightly controlled by a network of signaling routes, in which Notch cross-talks with several other pathways, such as the $\mathrm{Wnt}^{21}$ the $\mathrm{PKB} / \mathrm{Akt} / \mathrm{mTOR}^{22}$ and the JAK/STAT pathway. ${ }^{18,23}$

The Notch pathway is also active in mouse hematopoetic stem cells and its function is necessary to maintain an undifferentiated state and to prevent lineage commitment. ${ }^{21}$ Immortalized, pluripotent, cytokine-dependent hematopoetic cell lines can be established by transfection with a constitutively active Notch1 construct. ${ }^{24}$ Ligand-activated Notch enhances the proliferation of hematopoetic stem and progenitor cells, and regulates their differentiation potential. ${ }^{25,26}$ However, inhibitory effects of the ligands have also been published, ${ }^{27}$ which suggests that responsiveness to Notchsignals is likely to be cell type and context dependent. ${ }^{13}$ The role of Notch-signaling has been demonstrated in endothelial arteriovenous specification as well. ${ }^{28}$

\section{Multipotent adult progenitor cells}

Stem cells have gained tremendous scientific interest in the last decade as they hold great potential for the treatment of degenerative or inherited diseases. Embryonic stem cells are pluripotent and can differentiate to virtually all cell lineages; however, undifferentiated embryonic stem cells are prone to teratoma formation when injected in vivo, and the creation of human embryonic stem cells remains ethically controversial. ${ }^{29}$ Tissue specific adult stem cells were originally thought to have more restricted potential, but research in recent years has shown that they may still be capable of differentiating into cells other than the tissue of origin. ${ }^{30}$ However, this remarkable plasticity is currently difficult to exploit in a therapeutical setting. Multipotent adult progenitor cells may represent a new, clinically useful and ethically acceptable source of pluripotent stem cells.

Multipotent adult progenitor cells (MAPCs) have been isolated from the adherent fraction of mouse, rat and human bone marrow cells, as well as murine muscle and brain..$^{31-33}$ MAPCs can differentiate into several ectodermal, mesodermal and endodermal cell types in vitro, ${ }^{34,35}$ and transgenes from at least some of the lines have been demonstrated in almost all cell types of the three germ layers after injection of MAPCs into a mouse blastocyst. They can be maintained in culture for more than 120 population doublings with a normal karyotype. Of note, cell lines with different expression levels of the transcription factor POU5F1 (Oct4) are isolated from murine and rat bone marrow when cultured under MAPC conditions. ${ }^{36,37}$ Cells with higher expression levels of POU5F1 ( $\triangle \mathrm{CT}$ levels compared with the housekeeping gene GAPDH between 2 and 8; high-Oct4 MAPCs) appear to differentiate more robustly to endothelial and endodermal cell types ${ }^{37}$ compared with cells expressing lower levels of POU5F1 ( $\triangle \mathrm{CT}$ levels compared with the housekeeping gene GAPDH $>8$; low-Oct4 MAPCs). It 
remains unknown whether the phenotype of MAPCs is culture induced or exists as such in vivo. However, AnjosAfonso et al, terming the cells pre-MSC, have isolated cells from mouse bone marrow based on SSEA1 expression, a cell surface determinant also present on ESCs. ${ }^{38}$ SSEA1+ cells express Oct4 and SSEA1- cells do not express Oct4 upon isolation from bone marrow. Furthermore, SSEA1cells cannot be induced to express Oct4 in culture, suggesting that if MAPCs are created in vitro, they can only be created from a subpopulation of tissue cells.

The routine use of MAPCs has been hampered by the requirement of tedious culture conditions and very low cell density, ${ }^{36}$ which is crucial for maintaining the stem cell phenotype; high cell density gradually leads to the loss of stem cell properties, more so in populations of cells that express lower levels of POU5F1 (Park Y et al, manuscript in preparation). The reason for this is not known, but soluble factors as well as cell contact dependent interactions may play an important role. Preliminary gene expression array data showed that the expression of Notch3 and HES-1 increased when MAPCs expressing low levels of POU5F1 were allowed to proliferate to confluence (Lenvik T, Verfaillie CM, unpublished observations). Given the importance of Notch in cell-cell interactions, and its role in stem cell maintenance and differentiation, it is likely to contribute to the biological properties of MAPCs as well.

In the present work we characterized the gene expression of Notch pathway elements in rodent MAPCs expressing Oct4 albeit at low level, which provides a functional basis for the modulation of the signal. In addition, several components of the pathway were identified, which were themselves target genes of Notch signaling.

\section{Materials and Methods}

\section{Cell isolation and culture}

Mouse and rat multipotent adult progenitor cells (MAPCs) were isolated from the bone marrow, brain and skeletal muscle of 3-5 week old ROSA26 mice and from the bone marrow of Sprague-Dawley rats and cultured with a modification of a previously described procedure. ${ }^{33}$ All protocols were approved by the University of Minnesota Institutional Animal Care and Use Committee. Briefly, cells were seeded on plates coated with $10 \mathrm{ng} / \mathrm{ml}$ (for rat) or $100 \mathrm{ng} / \mathrm{ml}$ (for mouse) fibronectin (FN; Sigma, St. Louis, MO) in expansion medium at $6 \times 10^{5}$ cells $/ \mathrm{cm}^{2}$ and cultured at high density for 3-4 weeks. After 3-4 weeks, $\mathrm{CD}^{4} 5^{+} /$Ter $119^{+}$cells were depleted using micromagnetic beads (Miltenyi Biotec, Auburn, CA), replated at 10 cells/well in FN coated 96-well plates and expanded at densities between 100 and 1000 cells $/ \mathrm{cm}^{2}$.

MAPC expansion medium consisted of 60\% DMEM-low glucose (Gibco BRL, Carlsbad, CA) and 40\% MCDB-201
(Sigma) supplemented with 1X insulin-transferrin-selenium (ITS) (Sigma), 1X linoleic acid-bovine serum albumin (LABSA) (Sigma), $10^{-9} \mathrm{M}$ dexamethasone (Sigma), $10^{-4} \mathrm{M}$ ascorbic acid 2-phosphate (Sigma), 100 units of penicillin/1000 units of streptomycin (Cellgro, Herndon, VA), 2\% fetal bovine serum (FBS; Hyclone, Logan, UT), 10ng/ml hPDGFBB (R\&D Systems, Minneapolis, MN), $10 \mathrm{ng} / \mathrm{ml} \mathrm{mEGF}$ (Sigma) and 1000 units/ml mLIF (ESGRO, Temecula, CA). In certain mouse cell cultures dexamethasone was omitted, ITS was replaced by $1 \mathrm{X}$ SITE supplement (Sigma), LA-BSA was reduced to $0.2 \mathrm{X}$, and Chemically Defined Lipid Concentrate (Gibco), $0.8 \mathrm{mg} / \mathrm{ml} \mathrm{BSA} \mathrm{(Sigma)} \mathrm{and} 55 \mu \mathrm{M} \beta$-mercaptoethanol ( $\beta$-ME, Gibco) was added. Mouse cells were grown on plates (Nalge Nunc International, Rochester, NY)

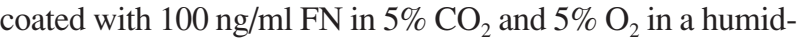
ified chamber. Rat cells were grown in flasks (Corning, Corning, NY) coated with $10 \mathrm{ng} / \mathrm{ml} \mathrm{FN}$ in $5 \% \mathrm{CO}_{2}$ and $20 \%$ $\mathrm{O}_{2}$ in a humidified chamber. Cell density (200-1000 cells $/ \mathrm{cm}^{2}$ ) was maintained by detaching cells with $0.25 \%$ trypsin (Cellgro) and replating every 36-48 hours. Photographs were taken on a Zeiss microscope with a Nikon Coolpix digital camera.

Cells were cultured at high density $\left(>2 \times 10^{4}\right.$ cells $\left./ \mathrm{cm}^{2}\right)$ to assess density-dependent changes. Tri-lineage differentiation potential of MAPCs was determined as described previously. ${ }^{33}$

The R1 mouse embryonic stem cell line was a kind gift from Dr. Janet Rossant (Mount Sinai Hospital, Toronto, Canada).

Cell cultures with Delta-1 Pxt-IgG $^{\text {ing }}$

Delta- $1^{\text {ext-IgG }}$ - a ligand of the Notch receptor - was kindly provided by Irwin D. Bernstein (Fred Hutchinson Cancer Research Center, Seattle, WA, USA). Four-well plastic chamber slides (Nalge Nunc) or 24-well plates (Corning) were coated overnight at $4^{\circ} \mathrm{C}$ with $10 \mu \mathrm{g} / \mathrm{ml}$ Delta- $1^{\text {ext-IgG }}$ in $10 \mathrm{ng} / \mathrm{ml} \mathrm{FN}$. Control wells were coated with $10 \mu \mathrm{g} / \mathrm{ml}$ $\mathrm{hIgG}$ (Sigma) in $10 \mathrm{ng} / \mathrm{ml}$ FN. (A second control was also included with cells grown on FN only - values from the two types of control were not different from each other.) Mouse or rat MAPCs were seeded at $5 \times 10^{4}$ cells/well in complete MAPC expansion medium (= medium with growth factors) or in medium without PDGF-BB, EGF, LIF and $\beta$-ME (= medium without growth factors), and cultured in a humidified chamber. $\mathrm{CO}_{2}$ and $\mathrm{O}_{2}$ concentrations corresponded to MAPC culture conditions as per cell type. Cells were lysed for RNA after 48 or 96 hours.

\section{$R N A$ isolation and quantitative real-time PCR}

RNA was extracted with the RNeasy Mini kit (Qiagen, Valencia, CA) and treated with DNAse (DNA-free ${ }^{\mathrm{TM}}$; Ambion, Austin, TX). Reverse transcription was per- 
Table 1. Primers used for qRT-PCR

\begin{tabular}{|c|c|c|}
\hline Target gene & Forward primer & Reverse primer \\
\hline Mouse and rat Notch1 & TGGAGCTACCTGCACTGACTATC & TCTCCTCGGAGCAGTTAGACC \\
\hline Mouse Notch2 & CAAAGAAAGCCAAGGCTGAG & GTTCTGCCTGAGGAGGAGTG \\
\hline Rat Notch2 & CCTGAACGGGCAGTACATTT & GCGTAGCCCTTCAGACACTC \\
\hline Mouse and rat Notch3 & ATACACTGGCCCCTTCTGTG & GTCGAGGCAAGAACAGGAAA \\
\hline Mouse Notch4 & TGAATCGGAGGTTCTGGATG & CCACAGAAGACGGCTGACA \\
\hline Mouse Jagged1 & AAAGACCACTGCCGTACCAC & GGGGACCACAGACGTTAGAA \\
\hline Mouse Jagged2 & CTGCCATGAAAACATTGACG & CGTTGGGATTGATGTCACAG \\
\hline Mouse Delta1 & CTGTGACAAACCAGGGGAGT & GACAACCTGGGTATCGGATG \\
\hline Mosue Delta4 & CAGAGACTTCGCCAGGAAAC & TCATTTTGCTCGTCTGTTCG \\
\hline Mouse HES-1 & ACACCGGACAAACCAAAGAC & ATGCCGGGAGCTATCTTTCT \\
\hline Rat HES-1 & AAAGATAGCTCCCGGCATTC & CCTCACACGTGGACAGGAA \\
\hline Mouse HERP1 & GCGTCGGGATCGAATAAATA & AGCATGGGCATCAAAGTAGC \\
\hline Mouse CBF1 & СТССАСССАAACGACTCACTA & GAAGAATGAGCACTGTTTGATCC \\
\hline Mouse Deltex1 & CTCCCCGTGAAGAACTTGAA & CACGTCGCTTTTGCTTACTG \\
\hline Mouse Numb & CGGGAAAGAAAGCAGTGAAG & AGTGGTGCCATCACGACATA \\
\hline Mouse Presenilin-1 & AAGTACCTCCCCGAATGGAC & TCAGCCATATTCACCAACCA \\
\hline Mouse Presenilin-2 & CGTGTCGTGTTTACTTCGTGA & CTGGTGACAAGACAGGTAGCAC \\
\hline Mouse Lunatic Fringe & CTGCAAGATGGCTGTGGAGTA & CGGAGGTTGACGTAGTTGTCAT \\
\hline Mouse Manic Fringe & CGTGGTCACCAACTGTTCTG & GCTTGCCCACATAGACATCA \\
\hline Mouse Radical Fringe & CTGCCGTCTGGTGCTATTTT & AAAGCTCCСТCAACСCTGTT \\
\hline Mouse Oct4 (POU5F1) & CCAATCAGCTTGGGCTAGAG & CCTGGGAAAGGTGTCCTGTA \\
\hline Rat Oct4 (POU5F1) & CTGTAACCGGCGCCAGAA & TGCATGGGAGAGCCCAGA \\
\hline Mouse GAPDH & CATGGCCTTCCGTGTTCCTA & CTGGTCCTCAGTGTAGCCCAA \\
\hline
\end{tabular}

formed with the SuperScript ${ }^{\mathrm{TM}}$ First Strand Synthesis kit (Invitrogen, Carslbad, CA). Twenty-five ng cDNA underwent 40 cycles of amplification (ABI PRISM 7700; Perkin Elmer, Applied Biosystems, Foster City, CA) with a two step PCR reaction $\left(95^{\circ} \mathrm{C}\right.$ for 15 seconds, $60^{\circ} \mathrm{C}$ for $60 \mathrm{sec}-$ onds) after initial denaturation $\left(95^{\circ} \mathrm{C}\right.$ for 10 minutes) with 100nM of each primer and 1X SYBR@ Green PCR Master Mix (Applied Biosystems). Primers used are listed in Table 1. Gene expression was normalized to the GAPDH housekeeping gene. Rat GAPDH primers were purchased from Applied Biosystems (TaqMan@ Rodent GAPDH Control Reagents).

\section{Statistics}

Paired Student's t-test was applied to evaluate significance; $p<0.05$ was considered statistically significant. Statistical analysis was performed using Microsoft Excel.

\section{Results}

Characterization of mouse and rat low-Oct4 MAPC

As we have recently described, isolation of clonal populations of cells under MAPC conditions yields populations of cells expressing variable levels of the ESC transcription factor Oct4 (POU5F1). ${ }^{36,37}$ The cells used in the current study expressed relatively low levels of Oct4: for the murine cells used, $\triangle \mathrm{CT}$ values of Oct4 compared with GAPDH were between 15 and 18; for rat cells the $\Delta \mathrm{CT}$ values were between 11 and 15 .

Notch-pathway profile in mouse MAPCs

The presence of Notch pathway transcripts was determined by real-time PCR in bone marrow derived mouse MAPCs; in addition, brain and muscle derived lines were included in some cases.

We found that transcripts for elements functioning at distinct levels of the signaling cascade were present in mouse MAPCs. Notch1, 2 and 3 receptors, the Jagged1 ligand, HES-1, Presenilin-1 and -2, CBF-1, Lunatic Fringe and Radical Fringe, and Numb transcripts were abundant in mouse MAPCs. Jagged2, Delta1, Notch4, Delta4, HERP-1, Deltex and Manic Fringe were expressed at low to undetectable levels.

When mouse MAPCs were compared to mouse ESCs, we found that Notch1 expression was similar in the two cell types; Notch2 expression was lower (about 6-fold), Notch3 expression was substantially higher (about 32fold) and HES-1 expression was slightly higher (two to threefold) in mouse ESCs. Notch4, Jagged1 and 2, Delta1, Presenilins, CBF-1, Lunatic Fringe, Manic Fringe, Radical Fringe and Numb were readily detectable; HERP-1 and Deltex were moderately expressed in mouse ES cells. Delta4 was absent in mouse ESCs as well. 

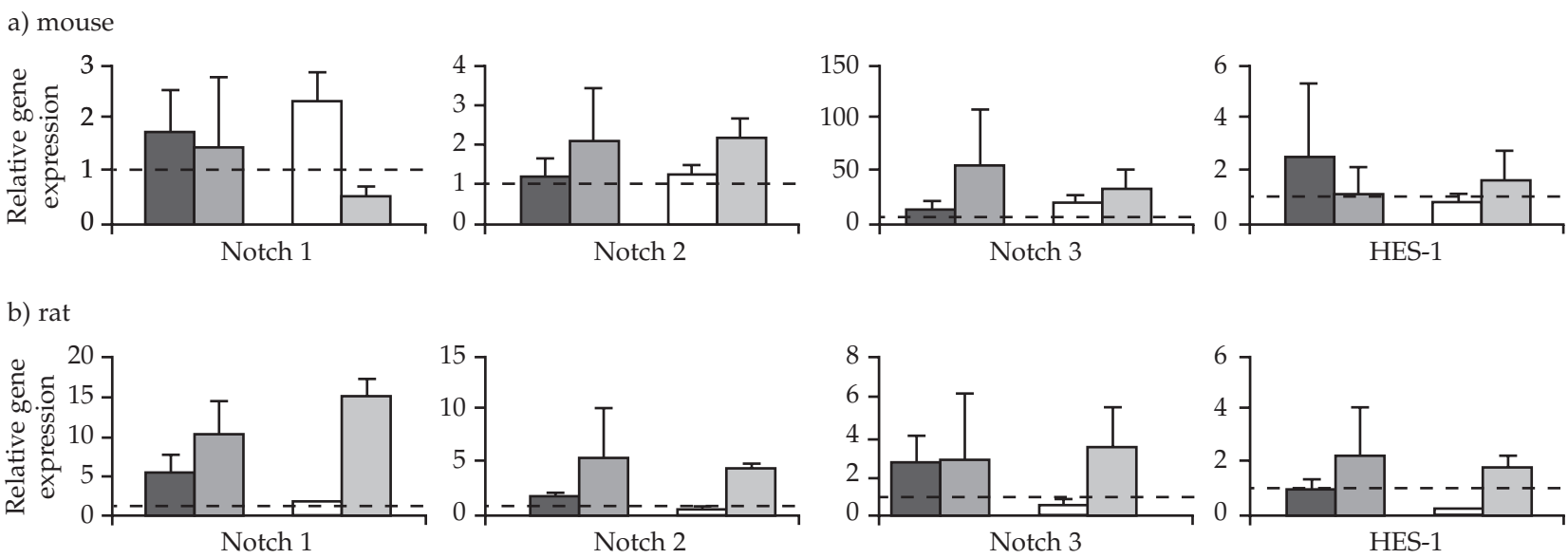

$48 \mathrm{~h}$

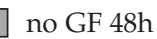

$96 \mathrm{~h}$

no GF $96 h$

Figure 1. Cell density dependent gene expression in (a) mouse and (b) rat low-Oct4-MAPCs. Relative gene expression of cells cultured at high cell density compared to cells cultured at low (MAPC) density $(=1$, indicated as a dashed line). Values are normalized to GAPDH. (GF: medium with EGF, PDGF and LIF; no GF: medium without EGF, PDGF and LIF; means and SD are shown for two to three independent experiments.)

\section{High cell density differentially regulates gene expression} of Notch pathway elements

To assess short-term transcriptional changes induced by high cell density, mouse and rat MAPCs were cultured at $5 \times 10^{4}$ cells/well in 4-well chamber slides in medium with or without EGF, PDGF and LIF, and gene expression was evaluated after 48 and 96 hours. Expression levels of Notch1, Notch2 and HES-1 in mouse MAPCs were not significantly altered upon maintenance at high cell density. However, Notch3 was significantly up-regulated in cultures with high cell density, which could still be observed after 96 hours (Fig. 1a); HERP-1 was also up-regulated at 48 hours, but its levels were still low and fell back to almost control values after 96 hours (not shown).

High cell density also influenced Notch-receptor expression in rat MAPCs (Fig. 1b): Notch-1 transcripts increased at 48 hours in medium with growth factors, and both at 48 and 96 hours in medium without growth factors. Notch-2 and Notch-3 expression was increased, albeit to a lesser extent. Changes in HES-1 expression were moderate.
Taken together, mRNA expression of Notch-pathway components were differentially regulated by cell density in both murine and rat MAPCs.

\section{Elements of the Notch pathway are target genes}

of Deltal signaling in mouse and rat MAPCs

To test whether the Notch ligand Delta1 can elicit signaling through Notch receptors, MAPCs were cultured on platebound Delta- $1^{\text {ext-IgG }}$ in MAPC medium with or without growth factors. Delta1 treatment significantly increased HES-1 mRNA expression in mouse MAPCs, both in the presence and the absence of growth factors; this increase was sustained, and still detectable after 96 hours of culture. HERP-1 was dramatically up-regulated at all time points tested. Delta1 also up-regulated Notch1 and Notch3, whereas Notch2 levels did not show significant changes (Table 2).

A similar effect was observed in rat MAPCs: the presence of the ligand significantly increased Notch-1, Notch3 and HES-1 expression in all conditions tested. Notch2 mRNA was also up-regulated in medium with growth fac-

Table 2. Average fold expression changes of Notch pathway genes in mouse low-Oct4-MAPCs grown on Delta-1 ${ }^{\text {ext-IgG }}$ in complete MAPC medium or in medium without growth factors (no GF).

\begin{tabular}{lcrrr}
\hline & \multicolumn{1}{c}{$48 h$} & no GF $48 h$ & \multicolumn{1}{c}{$96 h$} & no GF 96h \\
\hline Notch1 & $4.88( \pm 1.73) \mathrm{x}$ & $5.40( \pm 1.67) \mathrm{x}$ & $2.2( \pm 0.81) \mathrm{x}$ & $8.2( \pm 2.26) \mathrm{x}$ \\
Notch2 & $0.7( \pm 0.35) \mathrm{x}$ & $0.8( \pm 0.11) \mathrm{x}$ & $0.6( \pm 0.12) \mathrm{x}$ & $0.6( \pm 0.22) \mathrm{x}$ \\
Notch3 & $46.6( \pm 22.38) \mathrm{x}$ & $48.3( \pm 2.25) \mathrm{x}$ & $4.8( \pm 1.03) \mathrm{x}$ & $53.3( \pm 17.05) \mathrm{x}$ \\
HES-1 & $6.1( \pm 2.94) \mathrm{x}$ & $10.4( \pm 6.01) \mathrm{x}$ & $8.5( \pm 3.46) \mathrm{x}$ & $9.1( \pm 3.19) \mathrm{x}$ \\
HERP-1 & $1030( \pm 989.65) \mathrm{x}$ & $99.1( \pm 2.91) \mathrm{x}$ & $27.3( \pm 7.15) \mathrm{x}$ & $1192.9( \pm 358.28) \mathrm{x}$ \\
\hline
\end{tabular}

Values are relative to control cells $(=1)$, normalized to GAPDH. (Means of two to three independent experiments \pm SD are shown.) 
Table 3. Average fold expression changes of Notch pathway genes in rat low-Oct4-MAPCs grown on Delta-1 ${ }^{\text {ext-IgG }}$ in complete MAPC medium or in medium without growth factors (no GF).

\begin{tabular}{lcccc}
\hline & $48 h$ & no GF $48 h$ & $96 h$ & no GF 96h \\
\hline Notch1 & $26.10( \pm 9.83) \mathrm{x}$ & $24.68( \pm 0.48) \mathrm{x}$ & $31.47( \pm 4.83) \mathrm{x}$ & $12.64( \pm 4.60) \mathrm{x}$ \\
Notch2 & $1.14( \pm 0.46) \mathrm{x}$ & $0.75( \pm 0.22) \mathrm{x}$ & $3.53( \pm 1.27) \mathrm{x}$ & $0.60( \pm 0.05) \mathrm{x}$ \\
Notch3 & $88.15( \pm 57.71) \mathrm{x}$ & $172.50( \pm 66.42) \mathrm{x}$ & $259.54( \pm 137.88) \mathrm{x}$ & $216.92( \pm 60.31) \mathrm{x}$ \\
HES-1 & $4.83( \pm 2.34) \mathrm{x}$ & $3.86( \pm 0.36) \mathrm{x}$ & $5.84( \pm 0.77) \mathrm{x}$ & $4.29( \pm 0.33) \mathrm{x}$ \\
\hline
\end{tabular}

Values are relative to control cells $(=1)$, normalized to GAPDH. (Means of two to three independent experiments \pm SD are shown.)

tors at 96 hours (Table 3). Thus, we can conclude that several components of the Notch pathway are transcriptional targets of Notch-signaling itself.

Delta1 treatment had an impact on cell morphology as well (Fig.2.). In mouse cell cultures, control cells exhibited an organized, islet-like pattern on the second day after seeding; this structure was loosened in ligand-treated cells. More strikingly, control rat cells acquired a polygonal shape and were confluent, whereas cells grown on Delta1 retained an elongated, slightly irregular shape, exhibiting a lower cell density and more detached cells than in control cultures.

\section{Discussion}

Notch has been widely studied in the context of stem cells, hoping that specific modulation of the signal may provide an in vitro tool for stem cell expansion and for the manipulation of lineage specific differentiation in the future. This may be of special interest in MAPCs, where in particular for populations that express relatively low levels of the ESC transcription factor POU5F1 - largescale culturing has been difficult because of the requirement of low cell density.

We demonstrated that most Notch-signaling components are present in mouse and rat low-Oct4-MAPCs. Presenilins, Notch1, 2 and 3 receptors, Jagged1 (and to a lesser extent, Jagged 2 and Delta1 ligands), CBF1, the target gene HES-1 and regulator molecules such as Numb, Lunatic Fringe and Radical Fringe were all detected; thus, it can be concluded that MAPCs possess the necessary elements required for a functional and fine-tunable Notch signal. In line with our results on rodent cells, human MAPCs have previously also been shown to express substantial Notch1,2,3 and Jagged1, but little Delta1 and Jagged2; however, human MAPCs also expressed some Delta4. ${ }^{39}$ In comparison, we found that mouse ESCs expressed substantially higher levels of Notch3 and lower levels of Notch2 than mouse low-Oct4MAPCs, which corresponds well with previously published results, where Notch1 and 3, and lower levels of Notch2 were reported in ESCs. ${ }^{40,16}$ These data suggest that, although stem cells share a number of functioning genes which contribute to their "stemness, ${ }^{41}$ these characteristic signatures may vary to some extent according to stem cell type.
Cell density had an impact on the expression of some signaling elements in low-Oct4 rodent MAPCs: Notch3 (as our previous unpublished microarray data suggested) and HERP transcripts increased following culture of low-Oct4 mouse MAPCs for 48-96h at high density, whereas expression of Notch1, Notch2, and - to a lesser extent - Notch3 was increased in low-Oct4 rat MAPCs cultured for 48-96h at high cell density. At least some of these changes are transient, as expression of some of these transcripts returned to baseline levels at 96 hours of culture at high density. The presence or absence of growth factors did not have a consistent impact on the expression of Notch pathway elements, however, they may, in some cases, help sustain cell density dependent transcriptional changes for longer time periods.

Notch signaling may have different target genes in distinct cell types. ${ }^{4}$ Immobilized Delta1 initiated signaling through Notch receptors in rodent MAPCs, and in addition to HES-1 (and HERP-1 in mouse cells), expression of Notch1 and Notch3 were increased. Delta1 was also reported to induce HES-1 and Notch3 expression in human CD34+ early hematopoetic cells, ${ }^{42}$ which suggests that Notch3 may also be a conserved Notch target in several species and cell types. Whether Notch1 and Notch3 are directly or indirectly regulated by Delta1 has yet to be determined. These transcriptional changes probably comprise a part of a biological feedback loop, which contributes to the tight control of cellular processes.

Notably, HES-1 and Notch1 were present in low density mouse MAPC cultures whereas HERP-1 and Notch3 were expressed at low levels, but all of them were inducible upon stimulation with Delta1. One possibility is that HES-1 expression is maintained by Notch-independent mechanisms when cells have little contact with each other. In fact, the TGF $\beta$, the JNK and the Ras/MAPK signaling pathways were shown to regulate HES-1 in epithelial, endothelial and neuroblastoma cell types, respectively. ${ }^{43-45}$ The up-regulation of HERP-1 and other target genes may require Notch-signaling mediated by ligands in the environment, and specific transcriptional changes may depend on signaling strength, time and other factors such as the presence and type of serum. ${ }^{46}$

The role of Notch during differentiation is not yet fully known. Yu et al found that HES-1 expression was up-reg- 

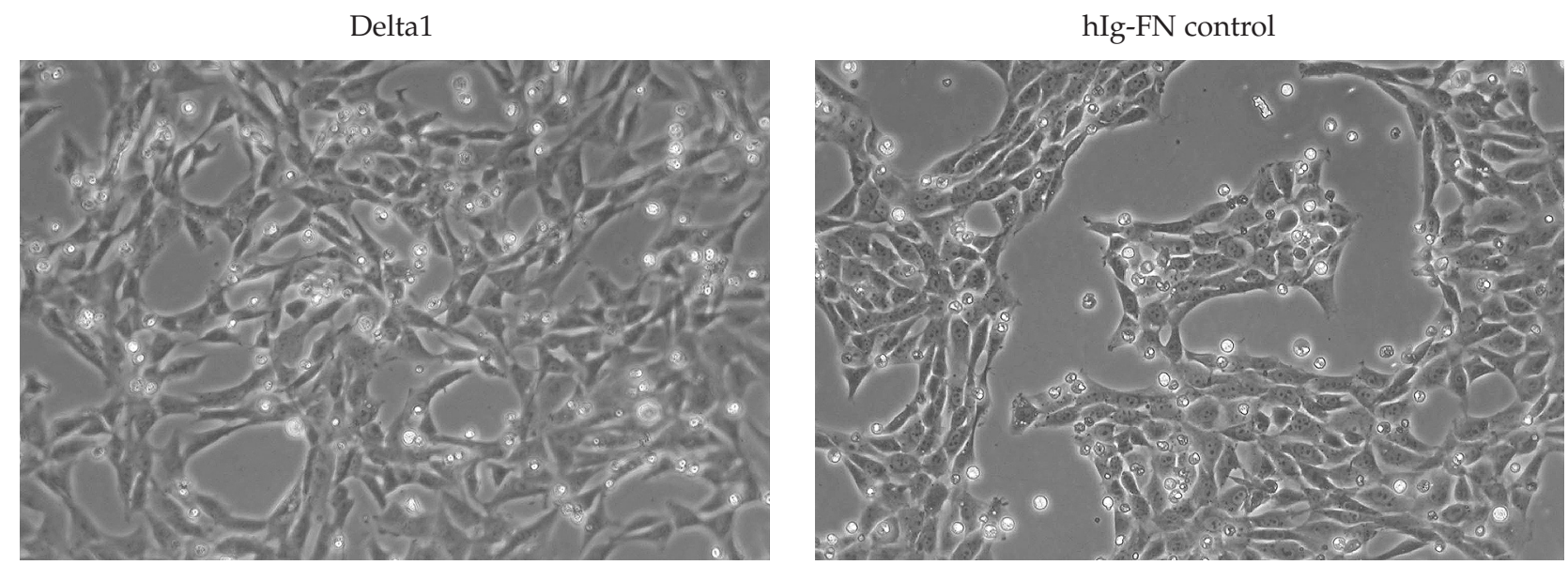

a) mouse
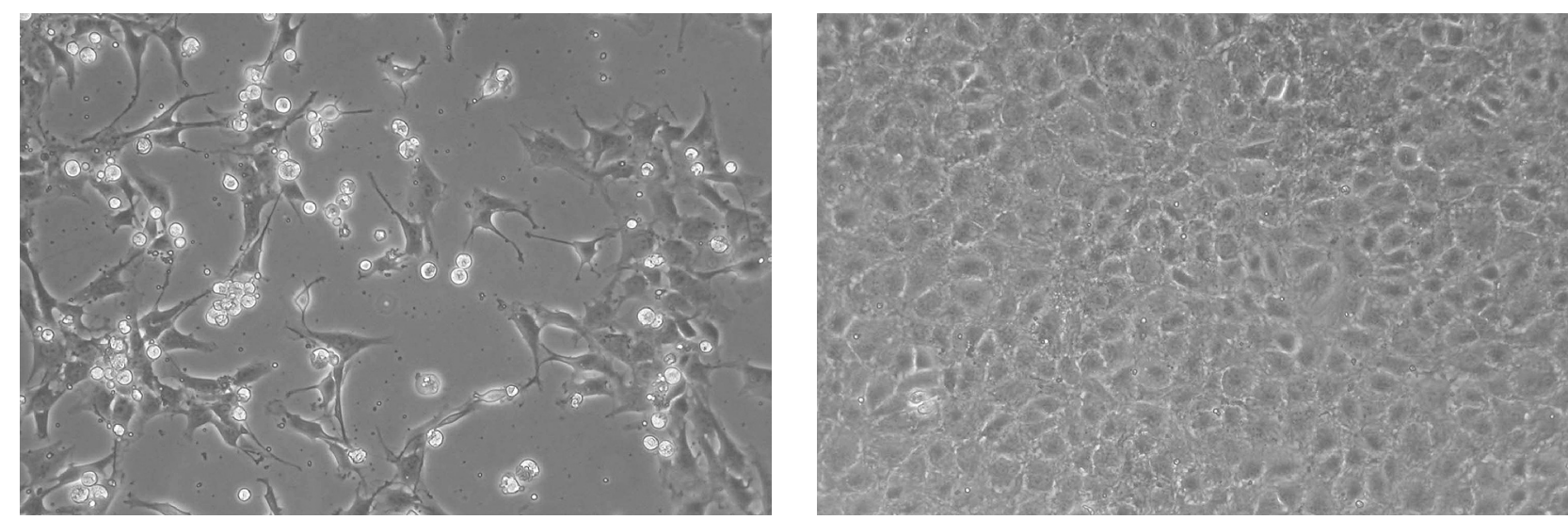

b) rat

Figure 2. Morphology of low-Oct4-MAPCs treated with Delta1 ligand for 2 days; (a) mouse, (b) rat cells (magnification: 200x; representative photos are shown).

ulated in human hematopoetic stem cells compared to more mature progenitors. ${ }^{47}$ In contrast, Noggle et al reported the activation of Notch signaling in cells differentiating from human embryonic stem cells. ${ }^{15}$ In preliminary experiments, Notch1, Notch3, Notch4, Jagged1, HES-1 and Numb transcripts increased remarkably by day 14 during neuronal differentiation of rat MAPCs, whereas Jagged2 was down-regulated (our unpublished observations), and some of these changes may also be attributable to an increase in Notch activity. Notch activation alone (in the absence of differentiation inducing conditions) was not sufficient to promote differentiation into a specific cell lineage, as determined by screening for the presence of lineage specific transcription factors (our unpublished observations), however, longer time periods may be necessary to detect such changes.

Taken together, we identified the components of the Notch-pathway in rodent low-Oct4 multipotent adult progenitor cells, and showed that the signaling pathway can be modulated in in vitro culture systems. Mouse and rat HES-
1 and mouse HERP-1 were shown to be transcriptional target genes of the signal in MAPCs. In addition, Notch1 and Notch3 receptors themselves were targets of Notch-signaling in both mouse and rat MAPCs as well. However, the exact transcriptional changes and functional consequences may be species specific. Future studies elucidating the function of Notch in cell fate specification in MAPCs, as well as investigation of Notch signaling pathways in MAPCs expressing different levels of Oct 4 will lead to a more thorough understanding of stem cell biology, which - hopefully - will result in the development of practical applications in cell therapy.

\section{Acknowledgement}

The Delta- $1^{\text {extlgG }}$ ligand was kindly provided by Irwin D. Bernstein (Fred Hutchinson Cancer Center, Seattle, WA, USA). The R1 mouse embryonic cell line was a kind gift from Dr. Janet Rossant (Mount Sinai Hospital, Toronto, Canada). I would like to thank April Breyer and Laura Lien for help with cell cultures and Mark Blackstad for help with PCR. 


\section{References}

1. Artavanis-Tsakonas S, Rand MD, Lake RJ: Notch signaling: cell fate control and signal integration in development. Science 284: 770-776, 1999.

2. Mumm JS, Kopan R: Notch Signaling: From the Outside In. Dev Biol 228: 151-165, 2000.

3. Jarriault S, Brou C, Logeat F, Schroeter EH, Kopan R, Israel $A$ : Signalling downstream of mammalian Notch. Nature 377: 355-358, 1995.

4. Iso T, Kedes L, Hamamori Y: HES and HERP Families: Multiple Effectors of the Notch Signaling Pathway. J Cellular Physiol 194: 237-255, 2003.

5. Fischer A, Gessler M: Delta-Notch - and then? Protein interactions and proposed modes of repression by Hes and Hey bHLH factors. Nucleic Acids Res 35: 4583-4596, 2007.

6. Liu WH, Lai MZ: Deltex Regulates T-Cell Activation by Targeted Degradation of Active MEKK1. Mol Cell Biol 25: $1367-$ 1378,2005

7. Kojika A, Griffin JD: Notch receptors and hematopoiesis. Exp Hematol 29: 1041-1052, 2001.

8. Anderson AC, Kitchens EA, Chan SW, St. Hill C, Jan YN, Zhong W, Robey EA: The Notch Regulator Numb Links the Notch and TCR Signaling Pathways. J Immunol 174: 890-897, 2005.

9. Hicks C, Johnston SH, diSibio G, Collazo A, Vogt TF, Weinmaster $G$ : Fringe differentially modulates Jagged1 and Delta1 signaling through Notch1 and Notch2. Nature Cell Biol 2: 515 520, 2000.

10. Milner LA, Bigas A: Notch as a Mediator of Cell Fate Determination in Hematopoiesis: Evidence and Speculation. Blood 93: 2431-2448, 1999.

11. Gaiano N, Fishell G: The Role of Notch in Promoting Glial and Neural Stem Cell Fates. Annu Rev Neurosci 25: 471-490, 2002.

12. Chiba S: Concise Review: Notch Signaling in Stem Cell Systems. Stem Cells 24: 2437-2447, 2006.

13. Karanu FN, Yuefei L, Gallacher L, Sakano S, Bhatia M: Differential response of primitive human CD34- and CD34+ hematopoietic cells to the Notch ligand Jagged-1. Leukemia 17: 1366-1374, 2003.

14. Walsh J, Andrews PW: Expression of Wnt and Notch pathway genes in a pluripotent human embryonal carcinoma cell line and embryonic stem cells. APMIS 111: 197-211, 2003.

15. Noggle $S A$, Weiler $D$, Condie BG: Notch Signaling Is Inactive but Inducible in Human Embryonic Stem Cells. Stem Cells 24: 1646-1653, 2006.

16. Rho JY, Yu K, Han JS, Chae JI, Koo DB, Yoon HS, Moon SY, Lee $K K$, Han YM: Transcriptional profiling of the developmentally important signalling pathways in human embryonic stem cells. Human Reproduction 21: 405-412, 2006.

17. Tokunaga A, Kohyama J, Yoshida T, Nakao K, Sawamoto K, Okano H: Mapping spatio-temporal activation of Notch signaling during neurogenesis and gliogenesis in the developing mouse brain. J Neurochem 90: 142-154, 2004.

18. Androutsellis-Theotokis A, Leker RR, Soldner F, Hoeppner DJ, Ravin R, Poser SW, Rueger MA, Bae SK, Kittappa R, McKay $R D G$ : Notch signalling regulates stem cell numbers in vitro and in vivo. Nature 442: 823-826, 2006.

19. Hitoshi S, Alexson T, Tropepe V, Donoviel D, Elia AJ, Nye JS, Conlon RA, Mak TW, Bernstein A, van der Kooy D: Notch pathway molecules are essential for the maintenance, but not the generation, of mammalian neural stem cells. Genes Dev 16: 846-858, 2002.

20. Fan X, Matsui W, Khaki L, Stearns D, Chun J, Li YM, Eberhart $C G$ : Notch Pathway Inhibition Depletes Stem-like Cells and
Blocks Engraftment in Embryonal Brain Tumors. Cancer Res 66: 7445-7452, 2006.

21. Duncan AW, Rattis FM, DiMascio LN, Congdon KL, Pazianos $G$, Zhao C, Yoon $K$, Cook JM, Willert K, Gaiano N, Reya T: Integration of Notch and Wnt signaling in hematopoietic stem cell maintenance. Nature Immunology 6: 314-322, 2005.

22. Mungamuri SK, Yang XH, Thor AD, Somasundaram K: Survival Signaling by Notch1: Mammalian Target or Rapamycin (mTOR)-Dependent Inhibition of p53. Cancer Res 66: 47154724, 2006.

23. Nagao $M$, Sugimori $M$, Nakafuku $M$ : Crosstalk between Notch and growth factor/cytokine signaling pathways in neural stem cells. Mol Cell Biol 27: 3982-3994, 2007.

24. Varnum-Finney $B, X u$ L, Brashem-Stein C, Nourigat C, Flowers D, Bakkour S, Pear WS, Bernstein ID: Pluripotent, cytokinedependent, hematopoietic stem cells are immortalized by constitutive Notch1 signaling. Nature Medicine 6: 1278-1281, 2000.

25. Jones P, May G, Healy L, Brown J, Hoyne G, Delassus S, Enver T: Stromal Expression of Jagged 1 Promotes Colony Formation by Fetal Hematopoietic Progenitor Cells. Blood 92: 1505-1511, 1998.

26. Karanu FN, Murdoch B, Miyabayashi T, Ohno M, Koremoto M, Gallacher L, Wu D, Itoh A, Sakano S, Bhatia M: Human homologues of Delta-1 and Delta-4 function as mitogenic regulators of primitive human hematopoietic cells. Blood 97: 1960-1967, 2000.

27. Walker L, Lynch M, Silverman S, Fraser J, Boulter J, Weinmaster $G$, Gasson JC: The Notch/Jagged Pathway Inhibits Proliferation of Human Hematopoietic Progenitors In Vitro. Stem Cells 17: 162-171, 1999.

28. Lanner F, Sohl M, Farnebo F: Functional arterial and venous fate is determined by graded VEGF signaling and notch status during embryonic stem cell differentiation. Arterioscler Thromb Vasc Biol 27: 487-493, 2007.

29. Gruen L, Grabel L: Concise review: scientific and ethical roadblocks to human embryonic stem cell therapy. Stem Cells 24: 2162-2169, 2006

30. Dezawa M, Kanno H, Hoshino M, Cho H, Matsumoto $N$, Itokazu Y, Tajima Y, Yamada H, Sawada H, Ishikawa H, Mimura T, Kitada M, Suzuki Y, Ide C: Specific induction of neuronal cells from bone marrow stromal cells and application for autologous transplantation. J Clin Invest 113: 1701-1710, 2004.

31. Reyes M, Lund T, Lenvik T, Aguiar D, Koodie L, Verfaillie CM: Purification and ex vivo expansion of postnatal human marrow mesodermal progenitor cells. Blood 98: 2615-2625, 2001.

32. Jiang Y, Jahargirdar BN, Reinhardt RL, Schwartz RE, Keene, $C D$, Ortiz-Gonzalez XR, Reyes $M$, Lenvik T, Lund T, Blackstad $M, D u J$, Aldrich S, Lisberg A, Low WC, Largaespada DA, Verfaillie $C M$ : Pluripotency of mesenchymal stem cells derived from adult marrow. Nature 418: 41-49, 2002.

33. Jiang Y, Vaessen B, Lenvik T, Blackstad M, Reyes $M$, Verfaillie $C M$ : Multipotent progenitor cells can be isolated from postnatal murine bone marrow, muscle, and brain. Exp Hematol 30: 896-904, 2002.

34. Schwartz RE, Reyes M, Koodie L, Jiang Y, Blackstad M, Lund T, Lenvik T, Johnson S, Hu WS, Verfaillie CM: Multipotent adult progenitor cells from bone marrow differentiate into functional hepatocyte-like cells. J Clin Invest 109: 1291-1302, 2002.

35. Jiang Y, Henderson D, Blackstad M, Chen A, Miller RF, Verfaillie $C M$ : Neuroectodermal differentiation from mouse multipotent adult progenitor cells. Proc Natl Acad Sci USA 100 Suppl 1: 11854-11860, 2003.

36. Breyer A, Estharabadi N, Oki M, Ulloa F, Nelson-Holte M, Lien $L$, Jian Y: Multipotent adult progenitor cell isolation and culture procedures. Exp Hematol 34: 1596-1601, 2006. 
37. Ulloa-Montoya F, Kidder BL, Pauwelyn KA, Chase LG, Luttun A, Crabbe A, Geraerts $M$, Sharov AA, Piao Y, Ko MS, Hu WS, Verfaillie $C M$ : Comparative transcriptome analysis of embryonic and adult stem cells with extended and limited differentiation capacity. Genome Biol 6: R163, 2007.

38. Anjos-Afonso $F$, Bonnet D: Nonhematopoietic/endothelial SSEA-1+ cells define the most primitive progenitors in the adult murine bone marrow mesenchymal compartment. Blood 193: 1298-306, 2007.

39. Aranguren XL, Luttun A, Clavel $C$, Moreno $C$, Abizanda $G$, Barajas MA, Pelacho B, Uriz M, Arana M, Echavarri A, Soriano $M$, Andreu EJ, Merino J, Garcia-Verdugo JM, Verfaillie $C M$, Prosper F: In vitro and in vivo arterial differentiation of human multipotent adult progenitor cells. Blood 109: 26342642, 2007.

40. Carlson ME, Conboy IM: Regulating the Notch pathway in embryonic, adult and old stem cells. Current Opinion Pharmacol 7: 1-7, 2007.

41. Ramalho-Santos $M$, Yoon S, Matsuzaki Y, Mulligan RC, Melton DA: "Stemness": Transcriptional Profiling of Embryonic and Adult Stem Cells. Science 298: 597-600, 2002.

42. Neves H, Weerkamp F, Gomes AC, Naber BAE, Gameiro P, Becker JD, Lucio P, Clode N, van Dongen JJM, Staal FJT,
Parreira L: Effects of Delta1 and Jagged1 on Early Human Hematopoiesis: Correlation with Expression of Notch Signaling-Related Genes in CD34+ Cells. Stem Cells 24: 13281337, 2006.

43. Zavadil J, Cermak L, Soto-Nieves N, Bottinger EP: Integration of TGF-beta/Smad and Jagged1/Notch signalling in epithelial-to-mesenchymal transition. EMBO J 23: 11551165, 2004.

44. Curry CL, Reed LL, Nickoloff BJ, Miele L, Foreman KE: Notch-independent regulation of Hes-1 expression by c-Jun Nterminal kinase signaling in human endothelial cells. Lab Invest 86: 842-852, 2006.

45. Stockhausen MT, Sjolund J, Axelson $H$ : Regulation of the Notch target gene Hes-1 by TGFalpha induced Ras/MAPK signaling in human neuroblastoma cells. Exp Cell Res 310: 218-228, 2005.

46. Yoshiura S, Ohtsuka T, Takenaka Y, Nagahara H, Yoshikawa K, Kageyama R: Ultradian oscillations of Stat, Smad, and Hes1 expression in response to serum. Proc Natl Acad Sci 104: 11292-11297, 2007.

47. Yu X, Alder JK, Chun JH, Friedman AD, Heimfeld S, Cheng L, Civin CI: HES1 inhibits cycling of hematopoietic progenitor cells via DNA binding. Stem Cells 24: 876-888, 2006. 